\title{
Parental history of lupus and rheumatoid arthritis and risk in offspring in a nationwide cohort study: does sex matter?
}

\author{
Emily C Somers, ${ }^{1,2,3}$ Sussie Antonsen, ${ }^{3}$ Lars Pedersen, ${ }^{3}$ Henrik Toft Sørensen ${ }^{3}$
}

\begin{abstract}
- An additional
supplementary appendix is published online only. To view the file please visit the journal online (http://ard.bmj.com/ content/early/recent)

'Department of Internal Medicine, Division of Rheumatology, University of Michigan, Ann Arbor, Michigan, USA

${ }^{2}$ Department of Environmental Health Sciences, University of Michigan, Ann Arbor, Michigan, USA

${ }^{3}$ Department of Clinical Epidemiology, Aarhus University Hospital, Olof Palmes Allé, Denmark
\end{abstract}

\section{Correspondence to} Emily C Somers, University of Michigan, Division of Rheumatology, 24 Frank Lloyd Wright Drive, PO Box 481, Ann Arbor, Michigan 48109-5358,

USA; emsomers@umich.edu

Accepted 9 April 2012

\begin{abstract}
Objectives To examine the familial risk of systemic lupus erythematosus (SLE) and rheumatoid arthritis (RA), including juvenile rheumatoid/idiopathic arthritis (JRA), in a population-based setting; and to determine whether patterns of transmission differ according to the sex of the parent or offspring, in order to provide insight into the potential impact of $\mathrm{X}$-chromosomal factors on sex disparities in these autoimmune diseases.
\end{abstract}

Methods A population-based cohort of parent-offspring triads from Denmark (1977-2010) was established. SLE and RA incidence rates among offspring were calculated, and Cox regression was performed to assess the sexspecific risk of disease in offspring according to maternal or paternal disease history.

Results Among 3513817 parent-offspring triads, there were 1258 SLE cases among offspring (1095 female, 163 male) and 9118 cases of RA/JRA (6086 female, 3032 male). Among female offspring, SLE risk was nearly the same according to maternal (HR 14.1) or paternal (HR 14.5) history $(p=N S)$; likewise among male offspring, risk according to maternal (HR 5.5) and paternal (no cases) history were similar $(p=N S)$. For RA, all risk estimates were similar, regardless of the sex of the offspring or parent (HR 2.6-2.9; $p=N S)$.

Conclusions The authors quantified the familial risk of SLE and RA in a nationwide cohort study. For both diseases, transmission was comparable among both female and male offspring of maternal and paternal cases. These data provide evidence at the population level that $X$-chromosomal factors do not play a major role in sex disparities associated with the risk of SLE and RA.

Like the majority of autoimmune diseases, systemic lupus erythematosus (SLE) and rheumatoid arthritis (RA) disproportionately affect women, with female to male ratios of up to $9: 1 .^{1}$ Although sex steroid hormones probably contribute to the increased incidence observed among women, this explanation is simplistic. ${ }^{2}$ Genomic differences between men and women may play a role in autoimmune and other immunological diseases, and X-chromosomal factors, including X-linked susceptibility genes or incomplete $\mathrm{X}$ inactivation, have been hypothesised to contribute to the female preponderance of these diseases. ${ }^{34}$ It is estimated that the $\mathrm{X}$ chromosome contains close to $6 \%$ of genomic DNA in humans, or approximately 1100 known genes. ${ }^{5}$ Recent studies have suggested potential alleles on the X chromosome that may be relevant to RA and SLE, ${ }^{67}$ and investigation of candidate genes on the $\mathrm{X}$ chromosome that may be associated with autoimmune disorders is ongoing.
Familial aggregation has been identified for many autoimmune diseases, including SLE and RA. ${ }^{8-14}$ For instance, based on data from case-control studies, it has been estimated that offspring of a parent with SLE have more than three times the risk of developing SLE compared with controls with no family history (OR 3.3, 95\% CI 1.2 to 8.6); ${ }^{15}$ a similar degree of risk for developing $\mathrm{RA}$ among offspring with an affected parent has been reported (OR 3.5, 95\% CI 1.1 to 10.8). ${ }^{16}$ However, familial data for SLE and RA have often been derived from multiplex families recruited for genetics studies, which by definition include families with more than one case of disease. Also, it is unclear whether risk differs for maternal versus paternal transmission, or according to the sex of the offspring. Men have single X chromosomes, with all cells having maternally derived alleles on the $\mathrm{X}$ chromosome. While women inherit both maternal and paternal X chromosomes, only a single 'active' $\mathrm{X}$ chromosome is normally expressed in each cell (transcription of the inactive $X$ is silenced). Epigenetic mechanisms (gene modifications other than alterations in the DNA sequence), such as DNA methylation, are responsible for inactivation of the second $\mathrm{X}$ chromosome. The process of $\mathrm{X}$ chromosome inactivation is purportedly random, and therefore is expected to yield approximately equivalent proportions of cells in women who express maternal or paternal $\mathrm{X}$ alleles. If there are important risk allele(s) on the X chromosome, male offspring of mothers with SLE or RA would be expected to have a higher risk of disease than male offspring of affected fathers, because sons do not inherit a paternal X chromosome. Female offspring, however, would be expected to experience an equivalent magnitude of familial association regardless of whether the parental proband was maternal or paternal. If such patterns were refuted utilising population-based data, it would suggest that X-linked chromosomes do not play a substantial role in disease risk. Identification of differential risks would provide aetiological clues.

Laboratory research related to the intersection of sex, genetics and epigenetics in autoimmune diseases is ongoing, with a lack of complementary epidemiological data. We conducted this population-based study, utilising Danish registry data, to further understanding of the familial risk of disease and sex disparities in the risk of two major systemic autoimmune diseases-RA and SLE. 


\section{METHODS}

\section{Study population}

This population-based cohort study used linked Danish health registries for the period 1 January 1977 to 1 January 2010. The Danish Civil Registration System was utilised to produce individual-level data linkages, and also to establish parent-offspring linkages, which are available from 1950 onward. The Danish National Registry of Patients provided diagnostic data, based on the International Classification of Diseases (ICD) coding structure (ICD-8 until 1993; ICD-10 from 1994 onward). This database records hospitalisations since 1977 and outpatient visits since 1995. Further details regarding Danish registry data are described elsewhere. ${ }^{17-19}$ This research was approved by the Danish ethical review boards and the Danish Data Protection Agency.

Cases of SLE and RA, including juvenile rheumatoid/idiopathic arthritis (JRA), were identified based on relevant ICD-8 and ICD-10 diagnostic codes (see supplementary appendix, available online only). The date of the first ICD code for a given disease in the patient record was considered the diagnosis date.

\section{Statistical methods}

The analysis included all offspring-parent triads followed up during the study period. SLE and RA history, including diagnosis dates, were determined for all offspring and parents. Analyses were carried out separately for female and male offspring, in order to investigate sex-specific effects. Crude incidence rates of disease among the offspring, according to maternal and paternal history of disease, were calculated by dividing the number of cases by person-time at risk, expressed per 100000 personyears. In order to take into account person-time at risk, Cox proportional hazards regression was performed, using a lefttruncated approach and with offspring age as the timescale. ${ }^{20}$

${ }^{21}$ Both maternal and paternal disease histories were included as covariates in the primary models. Sensitivity analyses were conducted to account for calendar period, by adjusting for the year of birth, in 5-year groups, in the modelling. Further sensitivity analyses were conducted in which families with more than one affected offspring were excluded, so that these families were not over-weighted in the analyses. The Wald $\chi 2$ statistic was used to compare hazard ratios (HR) between maternal and paternal history. Data management and analysis was performed using SAS v9.2 software.

\section{RESULTS}

The study population included 3513817 eligible parentoffspring triads. Of these, 1015 female offspring and 1344 male offspring had less than 1 day at risk (due to neonatal death) and were thus excluded from analyses incorporating person-time. There was a total of 1258 cases of SLE among offspring (1095 female, 163 male) and 9118 cases of RA/JRA among offspring (6086 female, 3032 male). Table 1 presents incidence rates and HR with $95 \%$ CI corresponding to maternal and paternal history of disease, stratified by the sex of the offspring.

A parental history of SLE was strongly associated with the risk of SLE in offspring (HR $>14.0$ among female offspring for either maternal or paternal history; HR 5.5 among male offspring for maternal history; HR zero for paternal history due to absence of cases). A parental history of RA was also associated with increased risk of RA among offspring at statistically significant levels, compared with offspring without a parental history of RA. However, magnitudes of association were weaker than those observed for SLE (HR ranging from 2.4 to 2.9 in female and male offspring). When JRA cases were included in the total for RA, HR were similar to those for RA cases alone (HR ranging from 2.4 to 2.7).

As presented in table 1, when HR for maternal versus paternal history of disease were compared according to the sex of

Table 1 Sex-specific incidence rates and HR for SLE and RA, including JRA according to the maternal or paternal history of disease, Denmark, 1977-2010

\begin{tabular}{|c|c|c|c|c|c|c|c|c|c|c|}
\hline \multirow[b]{2}{*}{$\begin{array}{l}\text { Parental history of } \\
\text { disease }\end{array}$} & \multicolumn{5}{|c|}{ Female offspring } & \multicolumn{5}{|c|}{ Male offspring } \\
\hline & No of cases & $\begin{array}{l}\text { Person-time } \\
\text { at risk }\end{array}$ & $\begin{array}{l}\text { Crude } \\
\text { rate/100 000 } \\
\text { person-years }\end{array}$ & HR $(95 \%$ Cl)* & p Valuet & No of cases & $\begin{array}{l}\text { Person-time } \\
\text { at risk }\end{array}$ & $\begin{array}{l}\text { Crude rate } \\
/ 100000 \\
\text { person-years }\end{array}$ & HR $(95 \%$ Cl)* & p Value $t$ \\
\hline \multicolumn{11}{|l|}{ Maternal SLE } \\
\hline No & 1078 & 40656405 & 2.7 & Referent & 0.9588 & 162 & 44269324 & 0.4 & Referent & 0.9753 \\
\hline Yes & 17 & 44889 & 36.3 & \multicolumn{2}{|l|}{14.1 (8.7 to 22.8 ) } & 1 & 48468 & 2.0 & 5.5 (0.8 to 39.3 ) & \\
\hline \multicolumn{11}{|l|}{ Paternal SLE } \\
\hline \multicolumn{11}{|l|}{ Maternal RA } \\
\hline No & 4301 & 40202250 & 10.7 & Referent & 0.7233 & 1882 & 43767476 & 4.3 & Referent & 0.4651 \\
\hline Yes & 203 & 483783 & 42.0 & \multicolumn{2}{|c|}{$2.7(2.4$ to 3.1$)$} & 86 & 541077 & 15.9 & 2.6 (2.1 to 3.2 ) & \\
\hline \multicolumn{11}{|l|}{ Paternal RA } \\
\hline No & 4394 & 40439961 & 10.9 & \multicolumn{2}{|l|}{ Referent } & 1916 & 44026469 & 4.4 & Referent & \\
\hline Yes & 110 & 246073 & 44.7 & \multicolumn{2}{|l|}{2.8 (2.4 to 3.4$)$} & 52 & 282083 & 18.4 & 2.9 (2.2 to 3.8$)$ & \\
\hline No & 5964 & 40427902 & 14.8 & \multicolumn{2}{|l|}{ Referent } & 2974 & 44017063 & 6.8 & Referent & \\
\hline Yes & 122 & 247517 & 49.3 & \multicolumn{2}{|l|}{2.7 (2.2 to 3.2 ) } & 58 & 283400 & 20.5 & 2.6 (2.0 to 3.4 ) & \\
\hline
\end{tabular}

${ }^{*}$ Adjusted for maternal/paternal history.

tp Value comparing maternal versus paternal history risk estimates.

$\ddagger$ Upper bound not calculated due to no cases among male offspring.

JRA, juvenile rheumatoid/idiopathic arthritis; SLE, systemic lupus erythematosus; RA, rheumatoid arthritis. 
Table 2 Sensitivity analyses adjusted for birth year and excluding families with more than one offspring with disease

\begin{tabular}{|c|c|c|c|c|c|c|c|c|}
\hline \multirow{3}{*}{$\begin{array}{l}\text { Parental history of } \\
\text { disease }\end{array}$} & \multicolumn{4}{|c|}{ Female offspring } & \multicolumn{4}{|c|}{ Male offspring } \\
\hline & \multicolumn{2}{|c|}{ Adjusted for birth year } & \multicolumn{2}{|c|}{$\begin{array}{l}\text { Excluding families with more } \\
\text { than one affected offspring }\end{array}$} & \multicolumn{2}{|c|}{ Adjusted for birth year } & \multicolumn{2}{|c|}{$\begin{array}{l}\text { Excluding families with more than one } \\
\text { affected offspring }\end{array}$} \\
\hline & HR $(95 \% \mathrm{Cl})^{*}$ & p Valuet & HR $(95 \%$ Cl)* & p Valuet & HR $(95 \% \mathrm{CI})^{*}$ & p Valuet & HR $(95 \% \mathrm{CI})^{*}$ & p Valuet \\
\hline \multicolumn{9}{|l|}{ Maternal SLE } \\
\hline No & Referent & 0.9059 & Referent & 0.7710 & Referent & 0.9872 & Referent & 0.9754 \\
\hline Yes & 14.1 (8.7 to 22.80 & & 12.7 (7.6 to 21.2$)$ & & $5.6(0.8$ to 39.6$)$ & & 5.6 (0.8 to 39.8$)$ & \\
\hline Yes & $15.0(6.2$ to 36.1$)$ & & $14.8(6.1$ to 35.6$)$ & & $0(0) \ddagger$ & & $0(0) \ddagger$ & \\
\hline \multicolumn{9}{|l|}{ Maternal RA } \\
\hline No & Referent & 0.7136 & Referent & 0.5984 & Referent & 0.4510 & Referent & 0.7208 \\
\hline Yes & $2.8(2.4$ to 3.2$)$ & & $2.6(2.2$ to 3.0$)$ & & 2.6 (2.1 to 3.2$)$ & & $2.5(2.0$ to 3.1$)$ & \\
\hline \multicolumn{9}{|l|}{ Paternal RA } \\
\hline No & Referent & & Referent & & Referent & & Referent & \\
\hline No & Referent & & Referent & & Referent & & Referent & \\
\hline Yes & $2.9(2.4$ to 3.5$)$ & & $2.6(2.2$ to 3.2$)$ & & $2.9(2.2$ to 3.7$)$ & & 2.4 (1.8 to 3.2$)$ & \\
\hline
\end{tabular}

*Also adjusted for maternal/paternal history.

tp Value comparing maternal versus paternal history risk estimates.

‡Upper bound not calculated due to no cases among male offspring.

JRA, juvenile rheumatoid/idiopathic arthritis; SLE, systemic lupus erythematosus; RA, rheumatoid arthritis.

the offspring, magnitudes of risk were similar regarding either parent, both for SLE and RA (all p values NS). Results did not differ appreciably after adjustment for calendar period (in 5-year groups; table 2).

There were 12 families with SLE in more than one offspring (all with SLE in two offspring). For RA, 132 families had the disease in more than one offspring (128 families with two offspring and four families with more than two offspring affected). Results from sensitivity analyses excluding families with more than one affected offspring yielded numbers similar to those from the main models (table 2).

\section{DISCUSSION}

While familial aggregation of SLE and RA has long been recognised, our study is unique in its population-based design and focus on intergenerational patterns between parents and their offspring, rather than within more broadly defined first or second degree kinships. In addition, we accounted for the age of the offspring and person-time at risk. We also analysed incident cases, instead of simply reporting proportions of prevalent cases among offspring of affected relatives.

Our data extend former research. We thus showed in the Danish population, that a parental history of SLE is associated with up to a 14-fold increased risk of SLE among offspring, compared with a negative parental history of SLE. The magnitude of this risk is substantially higher than previous reports, ${ }^{15}$ suggesting that earlier studies may have underestimated familial risk. In contrast, our estimates for RA (HR ranging from 2.6 to 2.9) correspond more closely to previous data. ${ }^{22}$ SLE and RA are both complex diseases with multifactorial aetiologies involving the interplay of genetic and environmental factors. Our data imply that the genetic basis of SLE may be stronger than that for RA. Other lines of epidemiological evidence, such as temporal trends, also lend credence to this theory. For instance, while data indicate that the incidence of SLE has been relatively stable over calendar time,$^{23}$ the incidence of RA in recent decades has been estimated to be decreasing, ${ }^{24} 25$ indicating a modulation of RA risk by environmental factors.

When we examined whether a parental history of disease had a differential impact according to the sex of the parent or offspring, we confirmed that female offspring are at greater risk of disease than male offspring. This is consistent with wellrecognised higher incidence rates among female offspring. As hypothesised, for both SLE and RA, similar magnitudes of risk were observed among female offspring in association with a maternal or paternal history of disease. However, our data did not support the hypothesis that among male offspring a maternal history of disease would be associated with a greater magnitude of risk compared with a paternal history of disease. Rather, similar levels of risk were also seen among male offspring with maternal versus paternal disease history. Our results remained consistent in sensitivity analyses accounting for calendar time, and after the exclusion of families with more than one affected offspring case.

An overarching question in autoimmune disease research is which factors drive the strong female preponderance of disease. The idea that sex-chromosomal factors are involved is intriguing, and epidemiological research is needed in concert with basic science research in this area. Candidate X-chromosomal genes that may be associated with autoimmune diseases are beginning to be identified. For example, at least two single nucleotide polymorphisms on the $\mathrm{X}$ chromosome (variants of TIMP1 and IL9R) have recently been associated with RA in genome-wide linkage and association studies. ${ }^{6}$ Sawalha et a ${ }^{26}$ demonstrated an association between variants of an X chromosome gene (MECP2) and SLE in two independent populations. Interleukin-1 receptor-associated kinase 1 (IRAK1), another gene located on the $\mathrm{X}$ chromosome, may be a disease-susceptibility factor in human lupus, and animal models suggest that blocking IRAK1 can prevent murine lupus. ${ }^{7}$ As MECP2 and IRAK1 are located in close proximity to each other (on Xq28), linkage disequilibrium at this locus could underlie the apparent 
separate genetic associations. Another line of investigation is the identification of X-chromosomal genes with functional relevance to autoimmune disease. For instance, abnormalities in apoptosis have been observed in autoimmune diseases such as SLE, ${ }^{27}$ and at least $17 \mathrm{X}$ chromosome genes, including CD40LG, have apoptosis listed as a gene ontology term. ${ }^{28}$ However, our epidemiological findings of similar magnitudes of risk, regardless of the sex of the affected parent, indicate that for both SLE and RA, genetic factors associated with the sex chromosomes do not play a major role in disease risk at the population level. Coupled with the observation that individual single nucleotide polymorphisms recognised as being associated with SLE and RA correspond to small magnitudes of risk ( $\mathrm{OR}$ individually $<2$ ), our findings may imply that epigenetic rather than genetic factors are relevant to the sex disparities observed in the risk of these autoimmune diseases.

Incomplete inactivation of the second $\mathrm{X}$ chromosome in women may be one epigenetic mechanism involved in autoimmune disease, by allowing the overexpression of X-chromosomal genes in women. Lu et al ${ }^{29}$ provided evidence that demethylation of regulatory sequences on the inactive $\mathrm{X}$ chromosome and associated overexpression may be a factor in autoimmune disease. They found that CD40LG (a B-cell co-stimulatory molecule, encoded on the X chromosome) is unmethylated in men, while women have both a methylated and an unmethylated copy. Moreover, they demonstrated in a series of experiments on $\mathrm{T}$ cells isolated from lupus patients that CD40LG is overexpressed on CD4 $\mathrm{T}$ cells in women, but not men, corresponding to demethylation of CD40LG in women. Research is ongoing to determine if similar findings apply to other genes on the inactive $\mathrm{X}$ chromosome. A non-genomic concept that should be considered in the context of the parental origin of effects is the transmission of non-inherited maternal antigens (NIMA), which can occur transplacentally or by breastfeeding. ${ }^{30}$ Exposure to NIMA may influence immune modelling, ${ }^{31}$ and NIMA have been associated with both an increased ${ }^{32-34}$ and decreased ${ }^{35}$ risk of RA, whereas data do not support a role for NIMA in association with the risk of SLE. ${ }^{36}$

Our results contrast with those from a US-based registry study of SLE multiplex families, in which $22 \%$ of 68 SLE parents with SLE offspring were men. This led the authors to infer that men were overrepresented as parents of offspring with SLE. ${ }^{37}$ However, because that study was composed of families with at least two SLE cases rather than being population based, it may have been subject to selection biases, such as the inclusion of cases with greater genetic risk or disease severity, or a greater tendency for men with affected offspring to participate due to the rarity of SLE in men.

A phenomenon termed the 'Carter effect', first described for pyloric stenosis, ${ }^{38}$ predicts a greater magnitude of disease transmission in the sex with the lower baseline predisposition for disease (men in the cases of SLE and RA), based on the theory that a greater genetic load would be necessary for disease penetrance in the less affected sex. Support for the Carter effect was reported for multiple sclerosis, another autoimmune disease with a female preponderance, ${ }^{39}$ but was refuted in another study. ${ }^{40}$ While a higher genetic load has recently been reported for men compared with women with SLE, ${ }^{41}$ our results do not provide support for the Carter effect in either SLE or RA.

A number of study limitations should be noted. First, SLE and RA cases included in the analysis were classified based on ICD codes, rather than the fulfilment of formal American College of Rheumatology classification criteria, and it is well known that registry data are not completely accurate. However, American
College of Rheumatology criteria also have limitations, and have been shown to have sensitivity and specificity of less than $90 \%$ in research populations other than the original test population. ${ }^{42} 43$ While there may have been some misclassification of case status, such misclassification would be expected to be non-differential, and would therefore be expected to attenuate the reported risk estimates. ${ }^{44}$ Due to the small number of male SLE patients (in particular among male offspring), there may have been insufficient power to detect potential sex-dependent effects for this diagnosis. Another concern is that family linkages were based on administrative data, not permitting us to confirm biological parental status. Also, we were unable to assess the contribution of environmental factors, which may also cluster in families, to disease expression.

A future direction will be to explore the possibility of genetic anticipation in the SLE and RA populations, which would be exhibited by a younger age of onset and increased disease severity among second generation cases. As a simple comparison of age of onset distributions from each generation is inappropriate due to statistical considerations such as right truncation, ${ }^{45}$ various methods have been developed for the study of genetic anticipation, including newer methods that incorporate data from unaffected family members. ${ }^{46-50}$ Another direction will be to investigate familial autoimmunity in broader terms, rather than focusing on the patterns of single diseases within families. Various combinations of autoimmune diseases have been shown to cluster within families and individuals, ${ }^{1} 5152$ and shared heritable pathogenic factors, such as dysregulation of the interferon- $\alpha$ system in several autoimmune conditions, have been suggested. ${ }^{5354}$ While autoimmune diseases may have genetic and environmental risk factors in common, the interplay of such factors may influence the particular autoimmune phenotypes that are expressed. 5556

In conclusion, our study shows a strong familial risk for SLE and a more moderate familial risk for RA. For both diseases, we found equivalent disease transmission among both female and male offspring of maternal compared with paternal cases. These results do not support the concept of the Carter effect in SLE or RA, and provide indirect evidence on a population level that $\mathrm{X}$-chromosomal factors do not play a major role in sex disparities observed for the risk of SLE and RA.

Acknowledgements The authors would like to thank Bruce Richardson for critical review of the manuscript.

Competing interests None.

Funding This study was supported by an Arthritis Foundation new investigator award and an Elizabeth C Crosby research award (both to ECS) and by the Aarhus University Clinical Research Foundation.

Provenance and peer review Not commissioned; externally peer reviewed.

\section{REFERENCES}

1. Cooper GS, Bynum ML, Somers EC. Recent insights in the epidemiology of autoimmune diseases: improved prevalence estimates and understanding of clustering of diseases. J Autoimmun 2009;33:197-207.

2. Whitacre CC. Sex differences in autoimmune disease. Nat Immunol 2001;2:777-80.

3. Invernizzi P. The $\mathrm{X}$ chromosome in female-predominant autoimmune diseases. Ann NY Acad Sci 2007;1110:57-64.

4. Invernizzi $\mathbf{P}$, Pasini $\mathrm{S}$, Selmi $\mathrm{C}$, et al. Female predominance and $\mathrm{X}$ chromosome defects in autoimmune diseases. J Autoimmun 2009;33:12-6.

5. Hernández-Molina G, Svyryd Y, Sánchez-Guerrero J, et al. The role of the $X$ chromosome in immunity and autoimmunity. Autoimmun Rev 2007;6:218-22.

6. Burkhardt J, Petit-Teixeira E, Teixeira VH, et al. Association of the X-chromosomal genes TIMP1 and IL9R with rheumatoid arthritis. J Rheumato/ 2009;36: 2149-57.

7. Jacob CO, Zhu J, Armstrong DL, et al. Identification of IRAK1 as a risk gene with critical role in the pathogenesis of systemic lupus erythematosus. Proc Natl Acad Sci U S A 2009;106:6256-61. 
8. Alarcón-Segovia D, Alarcón-Riquelme ME, Cardiel MH, et al. Familial aggregation of systemic lupus erythematosus, rheumatoid arthritis, and other autoimmune diseases in 1,177 lupus patients from the GLADEL cohort. Arthritis Rheum 2005;52:1138-47.

9. Anaya JM, Castiblanco J, Tobón GJ, et al. Familial clustering of autoimmune diseases in patients with type 1 diabetes mellitus. J Autoimmun 2006;26:208-14.

10. Anaya JM, Tobon GJ, Vega P, et al. Autoimmune disease aggregation in families with primary Sjögren's syndrome. J Rheumatol 2006;33:2227-34.

11. Criswell LA, Pfeiffer KA, Lum RF, et al. Analysis of families in the multiple autoimmune disease genetics consortium (MADGC) collection: the PTPN22 $620 \mathrm{~W}$ allele associates with multiple autoimmune phenotypes. Am J Hum Genet 2005;76:561-71.

12. Hudson M, Rojas-Villarraga A, Coral-Alvarado $\mathrm{P}$, et al. Polyautoimmunity and familial autoimmunity in systemic sclerosis. J Autoimmun 2008;31:156-9.

13. Rojas-Villarraga A, Diaz FJ, Calvo-Páramo E, et al. Familial disease, the HLA-DRB1 shared epitope and anti-CCP antibodies influence time at appearance of substantial joint damage in rheumatoid arthritis. J Autoimmun 2009;32:64-9.

14. Wolfe $\mathbf{F}$, Kleinheksel SM, Khan MA. Prevalence of familial occurrence in patients with rheumatoid arthritis. Br J Rheumatol 1988;27 (Suppl. 2):150-2.

15. Cooper GS, Dooley MA, Treadwell EL, et al. Risk factors for development of systemic lupus erythematosus: allergies, infections, and family history. $J$ Clin Epidemiol 2002:55:982-9

16. Koumantaki Y, Giziaki E, Linos A, et al. Family history as a risk factor for rheumatoid arthritis: a case-control study. J Rheumatol 1997;24:1522-6.

17. Frank L. Epidemiology. When an entire country is a cohort. Science 2000;287 2398-9.

18. Pedersen CB, Gøtzsche H, Møller JO, et al. The Danish Civil Registration System. A cohort of eight million persons. Dan Med Bull 2006;53:441-9.

19. Sørensen HT, Riis AH, Diaz LJ, et al. Familial risk of venous thromboembolism: a nationwide cohort study. J Thromb Haemost 2011;9:320-4.

20. Korn EL, Graubard BI, Midthune D. Time-to-event analysis of longitudinal follow-up of a survey: choice of the time-scale. Am J Epidemiol 1997;145:72-80.

21. Lamarca R, Alonso J, Gómez G, et al. Left-truncated data with age as time scale: an alternative for survival analysis in the elderly population. J Gerontol A Biol Sci Med Sci 1998; 53:M337-43.

22. Silman AJ, Pearson JE. Epidemiology and genetics of rheumatoid arthritis. Arthritis Res 2002; 4 (Suppl. 3):S265-72.

23. Somers EC, Thomas SL, Smeeth L, et al. Incidence of systemic lupus erythematosus in the United Kingdom, 1990-1999. Arthritis Rheum 2007;57:612-8.

24. Jacobsson LT, Hanson RL, Knowler WC, et al. Decreasing incidence and prevalence of rheumatoid arthritis in Pima Indians over a twenty-five-year period. Arthritis Rheum 1994:37:1158-65

25. Doran MF, Pond GR, Crowson CS, et al. Trends in incidence and mortality in rheumatoid arthritis in Rochester, Minnesota, over a forty-year period. Arthritis Rheum 2002; 46:625-31.

26. Sawalha AH, Webb R, Han S, et al. Common variants within MECP2 confer risk of systemic lupus erythematosus. PLOS ONE 2008;3:e1727.

27. Kaplan MJ. Apoptosis in systemic lupus erythematosus. Clin Immunol 2004;112:210-8.

28. Biggar RJ, Bergen AW, Poulsen GN. Impact of $x$ chromosome genes in explaining the excess risk of cancer in males. Am J Epidemiol 2009;170:65-71.

29. Lu Q, Wu A, Tesmer L, et al. Demethylation of CD40LG on the inactive $X$ in $T$ cells from women with lupus. J Immunol 2007:179:6352-8.

30. Zhou L, Yoshimura Y, Huang Y, et al. Two independent pathways of maternal cell transmission to offspring: through placenta during pregnancy and by breast-feeding after birth. Immunology 2000;101:570-80.

31. Mold JE, Michaëlsson J, Burt TD, et al. Maternal alloantigens promote the development of tolerogenic fetal regulatory T cells in utero. Science 2008:322:1562-5
32. van der Horst-Bruinsma IE, Hazes JM, Schreuder GM, et al. Influence of noninherited maternal HLA-DR antigens on susceptibility to rheumatoid arthritis. Ann Rheum Dis 1998:57:672-5.

33. Harney S, Newton J, Milicic A, et al. Non-inherited maternal HLA alleles are associated with rheumatoid arthritis. Rheumatology (Oxford) 2003:42:171-4.

34. Guthrie KA, Tishkevich NR, Nelson JL. Non-inherited maternal human leukocyte antigen alleles in susceptibility to familial rheumatoid arthritis. Ann Rheum Dis 2009:68:107-9

35. Feitsma AL, Worthington J, van der Helm-van Mil AH, et al. Protective effect of noninherited maternal HLA-DR antigens on rheumatoid arthritis development. Proc Natl Acad Sci U S A 2007;104:19966-70.

36. Bronson PG, Komorowski LK, Ramsay PP, et al. Analysis of maternal-offspring HLA compatibility, parent-of-origin effects, and noninherited maternal antigen effects for HLA-DRB1 in systemic lupus erythematosus. Arthritis Rheum 2010;62:1712-17.

37. Aggarwal R, Namjou B, Li S, et al. Male-only systemic lupus. J Rheumatol 2010;37:1480-7.

38. Carter CO. The inheritance of congenital pyloric stenosis. Br Med Bull 1961;17:251-4

39. Kantarci $\mathbf{O H}$, Barcellos LF, Atkinson EJ, et al. Men transmit MS more often to their children vs women: the Carter effect. Neurology 2006;67:305-10.

40. Herrera BM, Ramagopalan SV, Orton S, et al. Parental transmission of MS in a population-based Canadian cohort. Neurology 2007;69:1208-12.

41. Sawalha A, Strickland F, Somers E, et al. Genetic/epigenetic modeling of male lupus. Lupus 2010;19:95.

42. Tan EM, Cohen AS, Fries JF, et al. The 1982 revised criteria for the classification of systemic lupus erythematosus. Arthritis Rheum 1982;25:1271-7.

43. Somers EC, Marder W, Lewis EE, et al. Sensitivity and specificity of the ACR and Boston weighted classification criteria for SLE. Arthritis Rheum 2006;54:S428.

44. Copeland KT, Checkoway H, McMichael AJ, et al. Bias due to misclassification in the estimation of relative risk. Am J Epidemiol 1977;105:488-95.

45. Heiman GA, Hodge SE, Wickramaratne P, et al. Age-at-interview bias in anticipation studies: computer simulations and an example with panic disorder. Psychiatr Genet 1996;6:61-6.

46. Huang $\mathbf{J}$, Vieland V. A new statistical test for age-of-onset anticipation: application to bipolar disorder. Genet Epidemiol 1997;14:1091-6.

47. Rabinowitz D, Yang 0 . Testing for age-at-onset anticipation with affected parent-child pairs. Biometrics 1999;55:834-8.

48. Hsu L, Zhao LP, Malone KE, et al. Assessing changes in ages at onset over successive generation: an application to breast cancer. Genet Epidemiol 2000;18:17-32.

49. Larsen $\mathbf{K}$, Petersen J, Bernstein I, et al. A parametric model for analyzing anticipation in genetically predisposed families. Stat App/ Genet Mol Biol 2009;8:26.

50. Boonstra PS, Gruber SB, Raymond VM, et al. A review of statistical methods for testing genetic anticipation: looking for an answer in Lynch syndrome. Genet Epidemiol 2010;34:756-68.

51. Somers EC, Thomas SL, Smeeth L, et al. Autoimmune diseases co-occurring within individuals and within families: a systematic review. Epidemiology 2006;17:202-17.

52. Somers EC, Thomas SL, Smeeth L, et al. Are individuals with an autoimmune disease at higher risk of a second autoimmune disorder? Am J Epidemiol 2009;169:749-55

53. Niewold TB, Hua J, Lehman TJ, et al. High serum IFN-alpha activity is a heritable risk factor for systemic lupus erythematosus. Genes Immun 2007;8:492-502.

54. Niewold TB, Wu SC, Smith M, et al. Familial aggregation of autoimmune disease in juvenile dermatomyositis. Pediatrics 2011:127:e1239-46.

55. Lorber M, Gershwin ME, Shoenfeld Y. The coexistence of systemic lupus erythematosus with other autoimmune diseases: the kaleidoscope of autoimmunity. Semin Arthritis Rheum 1994;24:105-13.

56. Anaya JM, Corena R, Castiblanco J, et al. The kaleidoscope of autoimmunity: multiple autoimmune syndromes and familial autoimmunity. Expert Rev Clin Immunol 2007:3:623-35. 


\section{ARD \\ Parental history of lupus and rheumatoid arthritis and risk in offspring in a nationwide cohort study: does sex matter?}

Emily C Somers, Sussie Antonsen, Lars Pedersen, et al.

Ann Rheum Dis published online May 14, 2012

doi: 10.1136/annrheumdis-2011-201165

Updated information and services can be found at:

http://ard.bmj.com/content/early/2012/05/14/annrheumdis-2011-201165.full.html

These include:

Data Supplement

"Web Only Data"

http://ard.bmj.com/content/suppl/2012/05/14/annrheumdis-2011-201165.DC1.html

References This article cites 56 articles, 20 of which can be accessed free at: http://ard.bmj.com/content/early/2012/05/14/annrheumdis-2011-201165.full.html\#ref-list-1

$\mathbf{P}<\mathbf{P} \quad$ Published online May 14, 2012 in advance of the print journal.

Email alerting

Receive free email alerts when new articles cite this article. Sign up in service the box at the top right corner of the online article.

Advance online articles have been peer reviewed, accepted for publication, edited and typeset, but have not not yet appeared in the paper journal. Advance online articles are citable and establish publication priority; they are indexed by PubMed from initial publication. Citations to Advance online articles must include the digital object identifier (DOIs) and date of initial publication.

To request permissions go to:

http://group.bmj.com/group/rights-licensing/permissions

To order reprints go to:

http://journals.bmj.com/cgi/reprintform

To subscribe to BMJ go to:

http://group.bmj.com/subscribe/ 
Topic Articles on similar topics can be found in the following collections Collections

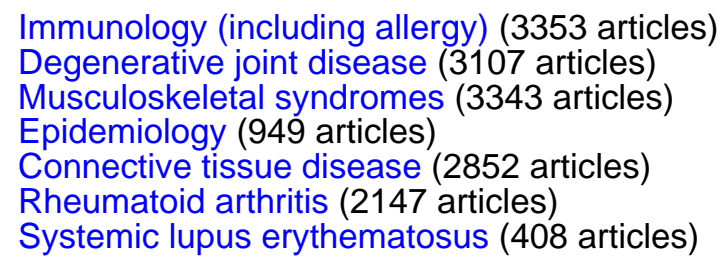

\section{Notes}

Advance online articles have been peer reviewed, accepted for publication, edited and typeset, but have not not yet appeared in the paper journal. Advance online articles are citable and establish publication priority; they are indexed by PubMed from initial publication. Citations to Advance online articles must include the digital object identifier (DOIs) and date of initial publication.

To request permissions go to:

http://group.bmj.com/group/rights-licensing/permissions

To order reprints go to:

http://journals.bmj.com/cgi/reprintform

To subscribe to BMJ go to:

http://group.bmj.com/subscribe/ 